\title{
PENDEKATAN METODE MARKOWITZ UNTUK OPTIMALISASI PORTOFOLIO DENGAN RISIKO EXPECTED SHORTFALL (ES) PADA SAHAM SYARIAH DILENGKAPI GUI MATLAB
}

\author{
Umiyatun Muthohiroh $^{1 *}$, Rita Rahmawati ${ }^{2}$, Dwi Ispriyanti ${ }^{3}$ \\ 1,2,3 Departemen Statistika, Fakultas Sains dan Matematika, Universitas Diponegoro \\ *umiyatunm@gmail.com
}

\begin{abstract}
A portfolio is a combination of two or more securities as investment targets for a certain period of time with certain conditions. The Markowitz method is a method that emphasizes efforts to maximize return expectations and can minimize stock risk. One method that can be used to measure risk is Expected Shortfall (ES). ES is an expected measure of risk whose value is above Value-at-Risk (VaR). To make it easier to calculate optimal portfolios with the Markowitz method and risk analysis with ES, an application was made using the Matlab GUI. The data used in this study consisted of three JII stocks including CPIN, CTRA, and BSDE stocks. The results of the portfolio formation with the Markowitz method obtained an optimal portfolio, namely the combination of CPIN $=34.7 \%$ and BSDE $=65.3 \%$ stocks. At the $95 \%$ confidence level, the ES value of 0.206727 is greater than the VaR value (0.15512).
\end{abstract}

Keywords: Portfolio, JII, Markowitz, Expected Shortfall, GUI Matlab

\section{PENDAHULUAN}

Investasi adalah komitmen atas sejumlah dana atau sumber daya lainnya yang dilakukan pada saat ini, dengan tujuan untuk memperoleh sejumlah keuntungan di masa yang akan dating (Tandelilin, 2010). Kegiatan investasi yang dilakukan investor akan menghasilkan keuntungan (return) dan sekaligus menghadapi risiko (risk). Strategi yang dapat digunakan untuk mengurangi risiko investasi adalah dengan membentuk portofolio. Menurut Maruddani dan Purbowati (2009), portofolio adalah gabungan dua atau lebih aset yang terpilih sebagai target investasi dari investor pada kurun waktu tertentu dengan suatu ketentuan tertentu, misalnya mengenai proporsi pembagian dana atau modal yang ditentukan.

Pembentukan portofolio akan membantu investor dalam mengambil keputusan untuk memilih portofolio mana yang optimal dan memiliki tingkat return yang diharapkan. Menurut Afriana dkk. (2017), terdapat tiga metode analisis yang dapat digunakan dalam membantu pembentukan portofolio yang optimal yaitu indeks tunggal, Capital Asset Pricing Model (CAPM), dan Markowitz. Metode markowitz merupakan salah satu metode yang tepat dalam memilih portofolio yang menekankan pada usaha memaksimalkan ekspektasi return dan dapat meminimumkan ketidakpastian atau risiko saham.

Pada hakekatnya pembentukan portofolio adalah untuk mengurangi resiko dengan diversifikasi. Diversifikasi adalah salah satu cara yang digunakan untuk mengurangi risiko melalui pembagian dana yang dimiliki ke dalam beberapa aset. Salah satu metode yang dapat digunakan untuk mengukur risiko adalah Expected Shortfall (ES). Secara umum, ES merupakan ekspektasi ukuran risiko yang nilainya di atas Value-at-Risk (VaR). Sedangkan $\mathrm{VaR}$ merupakan kerugian (return negatif) maksimum yang mungkin terjadi selama periode waktu pada tingkat kepercayaan tertentu.

Bagi masyarakat awam, menghitung nilai dan risiko portofolio bukanlah hal yang mudah. Pada penelitian ini akan dibahas pembentukan portofolio pada data closing price mingguan saham Jakarta Islamic Index (JII) periode 1 Januari 2018 sampai 28 Februari 
2020 dengan pendekatan metode Markowitz dan pengukuran risiko portofolio dengan Expected Shortfall (ES) menggunakan GUI Matlab.

\section{TINJAUAN PUSTAKA}

\subsection{Return}

Suatu perusahaan dapat menjual hak kepemilikannnya dalam bentuk saham (Maruddani, 2019). Saham adalah surat berharga sebagai bukti penyertaan atau pemilikan individu maupun institusi yang dikeluarkan oleh sebuah perusahaan yang berbentuk Perseroan Terbatas (PT). Saham juga dapat didefinisikan sebagai modal yang dikeluarkan perusahaan atau perseroan terbatas ke masyarakat agar seseorang atau badan usaha dapat memiliki sebagian hak dari perusahaan tersebut.

Menurut Maruddani dan Purbowati (2009), return merupakan salah satu faktor yang memotivasi investor untuk berinvestasi karena dari return investor bisa melihat hasil investasi. Rumus untuk menghitung return adalah sebagai berikut:

$$
R_{i, t}=\ln \left(\frac{P_{i t}}{P_{i(t-1)}}\right)
$$

$R_{i, t} \quad=$ Return aset ke-i pada waktu ke-t

$P_{i t} \quad=$ Harga aset ke-i pada waktu ke-t

$P_{i(t-1)}=$ Harga aset ke-i pada waktu ke-(t-1)

\subsection{Koefisien Korelasi}

Menurut Husnan (1982) dalam Afriana dkk. (2017), salah satu faktor yang mempengaruhi risiko portofolio yaitu korelasi. Dalam hal ini, korelasi merupakan hubungan antara tingkat keuntungan dari sekuritas-sekuritas yang terdapat dalam portofolio tersebut. Rumus untuk menghitung koefisien korelasi adalah sebagai berikut:

$$
\rho_{i j}=\frac{n \sum_{i=1, j=1}^{n} R_{i t} R_{j t}-\sum_{i=1}^{n} R_{i t} \sum_{j=1}^{n} R_{j t}}{\sqrt{\left[n \sum_{i=1}^{n} R_{i t}^{2}-\left(\sum_{i=1}^{n} R_{i t}\right)^{2}\right]\left[n \sum_{j=1}^{n} R_{j t}^{2}-\left(\sum_{j=1}^{n} R_{j t}\right)^{2}\right]}}
$$

Dengan:

$\rho_{i j} \quad=$ koefisien korelasi antar return aset ke-i dengan aset ke- $\mathrm{j}$

$R_{i t} \quad=$ return aset ke-i pada waktu ke-t

$R_{j t} \quad=$ return aset ke-j pada waktu ke-t

$n \quad=$ jumlah data return

\subsection{Risiko}

Dalam bidang finansial risiko sering dihadapkan dengan volatilitas atau penyimpangan/deviasi dari hasil investasi yang akan diterima dengan keuntungan yang diharapkan (Maruddani, 2010). Jika terdapat n (jumlah observasi) return, maka ekspektasi return dapat diestimasi dengan rata-rata sampel (mean) return

$$
\mu_{i}=\frac{1}{n} \sum_{t=1}^{n} R_{i t}
$$

Return rata-rata kemudian digunakan untuk mengestimasi varian tiap periode yaitu kuadrat standar deviasi per periode disebut varian per periode karena besarnya tergantung pada panjang waktu ketika return diukur.

$$
\sigma_{i}^{2}=\frac{1}{n-1} \sum_{t=1}^{n}\left(R_{i t}-\mu_{i}\right)^{2}
$$

Akar dari varian (standar deviasi) merupakan estimasi risiko dari harga saham yaitu 


$$
\sigma_{i}=\sqrt{\frac{1}{n-1} \sum_{t=1}^{n}\left(R_{i t}-\mu_{i}\right)^{2}}
$$

\subsection{Portofolio dengan Model Markowitz}

Teori Portofolio Markowitz merupakan teori portofolio yang menekankan pada usaha memaksimalkan ekspektasi return dan meminimumkan risiko untuk menyusun portofolio yang optimal. Melalui kosep diversifikasi (dengan pembentukan portofolio saham yang optimal), investor dapat memaksimalkan keuntungan yang diharapkan dari investasi dengan tingkat risiko tertentu atau berusaha meminimumkan risiko untuk sasaran tingkat keuntungan tertentu. Menurut Maruddani dan Purbowati (2009), permasalahan optimalisasi dapat diselesaikan dengan fungsi Lagrange yaitu:

$$
\begin{array}{cc}
L=\boldsymbol{w}^{\boldsymbol{T}} \sum \boldsymbol{w}+\lambda_{1}\left(\mu_{p}-\boldsymbol{w}^{\boldsymbol{T}} \boldsymbol{\mu}\right)+\lambda_{2}\left(1-\boldsymbol{w}^{\boldsymbol{T}} \mathbf{1}_{N}\right) \\
\text { Dimana, } & L=\text { fungsi Lagrange } \\
& \lambda=\text { faktor pengali Lagrange } \\
& \mu_{p}=\text { mean return portofolio }
\end{array}
$$

Untuk kasus portofolio dengan variansi efisien, tidak ada pembatasan pada mean portofolio $\left(\lambda_{1}=0\right)$, sehingga pembobotan pada Mean Variance Efficient Portfolio dengan return $\mathbf{X} \sim N_{N}(\boldsymbol{\mu}, \boldsymbol{\Sigma})$ adalah:

$$
w=\frac{\Sigma^{-1} 1_{N}}{\mathbf{1}_{N}^{T} \Sigma^{-1} 1_{N}}
$$

Dimana $\boldsymbol{\Sigma}^{\mathbf{- 1}}=$ invers matriks variansi-kovariansi

Menurut Abdurrakhman (2007) dalam Maruddani (2019), portofolio yang optimal adalah portofolio yang dipilih seorang investor dari sekian banyak pilihan yang ada pada kumpulan portofolio yang efisien.

Menurut Maruddani (2019), secara matematis return portofolio dari n aset pada waktu ke-t dapat ditulis sebagai berikut:

$R_{p, t}=\sum_{i=1}^{n} w_{i} \cdot R_{i, t}$

dengan, $R_{p, t} \quad=$ return portofolio pada waktu ke-t

$R_{i, t} \quad=$ return aset ke-i pada waktu ke-t

$w_{i} \quad=$ bobot setiap alokasi dana untuk aset

Sedangkan nilai expected return portofolio dapat dituliskan sebagai berikut:

$E\left(R_{p}\right)=\sum_{i=1}^{n} w_{i} \mu_{i}$

Sehingga nilai variansi dan standar deviasinya dapat dicari sebagai berikut :

Karena nilai $\sigma_{i j}=\sigma_{j i}$ maka didapatkan nilai varian:

$$
\begin{gathered}
\sigma_{p}^{2}=\sum_{i=1}^{n} W_{i}^{2} \sigma_{i}^{2}+2 \sum_{i=1}^{n} \sum_{j<i}^{n} w_{i} w_{j} \sigma_{i j}, \quad i \neq j \\
\sigma_{i j}=\rho_{i j} \sigma_{i} \sigma_{j}
\end{gathered}
$$

Rumus standar deviasi adalah sebagai berikut:

$$
\sigma_{p}=\sqrt{\sigma_{p}^{2}}
$$

\subsection{Distribusi Normal Multivariat}

Pengujian asumsi normal multivariat dapat dilakukan uji kecocokan distribusi Kolmogorov-Smirnov dengan hipotesis sebagai berikut :

Hipotesis:

$H_{0}: F\left(d_{j}^{2}\right)=F_{0}\left(d_{j}^{2}\right)$ untuk semua nilai $d_{j}^{2}$

$H_{1}: F\left(d_{j}^{2}\right) \neq F_{0}\left(d_{j}^{2}\right)$ untuk sekurang-kurangnya sebuah nilai $d_{j}^{2}$

Taraf Signifikansi: $\alpha$

Statistik Uji: 
$D=\sup _{d_{j}^{2}}\left|S\left(d_{j}^{2}\right)-F_{0}\left(d_{j}^{2}\right)\right|$

Dengan $\quad S\left(d_{j}^{2}\right)=$ fungsi peluang kumulatif yang dihitung dari jarak mahalanobis.

Kriteria Uji:

$$
F_{0}\left(d_{j}^{2}\right)=\text { fungsi peluang kumulatif dari distribusi Chi-Square. }
$$

$H_{0}$ ditolak jika $\mathrm{D}>\mathrm{D} *(\alpha)$

$\mathrm{D}^{*}(\alpha)$ merupakan nilai kritis yang diperoleh dari tabel Kolmogorov-Smirnov.

\subsection{Value at Risk (VaR)}

VaR diartikan sebagai estimasi kerugian maksimum yang akan dialami pada periode waktu dan tingkat kepercayaan tertentu (Jorion, 2002). Menghitung nilai VaR pada tingkat kepercayaan $(1-\alpha)$ dalam periode waktu $t$ hari yaitu

$$
\begin{aligned}
\operatorname{VaR}_{(1-\alpha)}(t) & =W_{0} R^{*} \sqrt{t} \\
\text { Dengan } \quad W_{0} & =\text { investasi awal aset } \\
\alpha & =\text { tingkat kesalahan } \\
t & =\text { holding period }
\end{aligned}
$$

Dalam mengestimasi nilai Value at Risk (VaR) baik pada aset tunggal maupun portofolio, simulasi Monte Carlo mempunyai beberapa jenis algoritma (Maruddani dan Purbowati, 2009). Namun pada intinya adalah melakukan simulasi dengan membangkitkan bilangan random berdasarkan karakteristik dari data yang akan dibangkitkan, yang kemudian digunakan untuk mengestimasi nilai VaR-nya. VaR dengan menggunakan metode simulasi Monte Carlo mengasumsikan bahwa return berdistribusi normal.

\subsection{Expected Shortfall (ES)}

Conditional Value at Risk merupakan suatu ukuran risiko yang memperhitungkan kerugian melebihi tingkat VaR (Rockafellar dan Uryasev, 2000). Conditional Value at Risk sering juga disebut Mean Excess Loss, Expected Shortfall, atau Tail VaR dan dianggap sebagai ukuran risiko yang lebih konsisten dari VaR. Expected Shorffall digunakan sebagai alternatif dalam pengukuran risiko yang berfungsi untuk mengurangi masalah yang terjadi pada VaR.

Jika $X$ merupakan peubah acak return yang saling bebas dan berdistribusi identik normal dengan rata-rata $\mu$ dan varian $\sigma^{2}$ (McNeil dan Embrechts, 2005). Peluang nilai return akan kurang dari sama dengan $\mathrm{VaR}$, dapat ditulis :

$$
P\left(X_{t+1} \leq V_{1-\alpha}\right)=1-\alpha
$$

VaR untuk $X \sim N\left(\mu, \sigma^{2}\right)$ dengan $\alpha \in(0,1)$ adalah

$$
\begin{gathered}
P\left(X_{t+1} \leq V_{1-\alpha}\right)=1-\alpha \\
P\left(\frac{X_{t+1}-\mu}{\sigma} \leq \frac{V_{1-\alpha}-\mu}{\sigma}\right)=1-\alpha
\end{gathered}
$$

$\phi\left(\frac{V_{1-\alpha}-\mu}{\sigma}\right)=1-\alpha$

$\frac{V_{1-\alpha}-\mu}{\sigma}=\phi^{-1}(1-\alpha)$

$V_{1-\alpha}=\mu+\phi^{-1}(1-\alpha) \sigma$

Selanjutnya, expected shortfall untuk distribusi normal dengan rata-rata $\mu$ dan varian $\sigma^{2}$ adalah :

$$
\mathrm{ES}_{1-\alpha}=\mu+\sigma\left(\frac{1}{\alpha} \int_{V_{1-\alpha}}^{\infty} x f_{V a R}(x) d x\right)
$$

ES untuk $X \sim N\left(\mu, \sigma^{2}\right)$ dengan $\alpha \in(0,1)$ adalah 


$$
\begin{aligned}
& \mathrm{ES}_{1-\alpha}=\mu+\sigma\left(\frac{1}{\alpha} \cdot \frac{1}{\sigma \sqrt{2 \pi}} \int_{V_{1-\alpha}}^{\infty} \exp \left[\frac{-x^{2}}{2}\right] x d x\right) \\
& \mathrm{ES}_{1-\alpha}=\mu+\sigma\left(\frac{1}{\alpha} \cdot\left[\frac{1}{2 \sqrt{2 \pi}} \exp \left[-\frac{x^{2}}{2}\right]\right]_{V_{1-\alpha}}^{\infty}\right)
\end{aligned}
$$

Sehingga prediksi expected shortfall sebagai berikut:

$\mathrm{ES}_{1-\alpha}=\mu+\sigma \frac{\phi\left(\widehat{V}_{1-\alpha}\right)}{\alpha}$

$\phi^{-1}$ dan $\phi$ adalah invers fungsi distribusi dan fungsi densitas normal standar.

ES untuk tingkat kepercayaan $(1-\alpha)$ dan holding periode t hari maka dapat ditulis dengan persamaan sebagai berikut:

$$
\mathrm{ES}_{1-\alpha}=\left(\mu+\sigma \frac{\phi\left(\widehat{V}_{1-\alpha}\right)}{\alpha}\right) \cdot \sqrt{t}
$$

\subsection{Graphic User Interface (GUI)}

GUI pada matlab lebih dikenal dengan nama GUIDE. GUI pada matlab merupakan sebuah aplikasi display dari matlab yang mengandung tugas, perintah, atau komponen program yang mempermudah pengguna dalam menjalankan sebuah program dalam Matlab.

\section{METODE PENELITIAN}

\subsection{Data}

Data yang digunakan dalam penelitian ini adalah data sekunder. Data ini merupakan data closing price mingguan saham anggota Jakarta Islamic Index (JII) sebagai dasar perhitungan return saham. Periode yang digunakan adalah 1 Januari 2018 sampai dengan 28 Februari 2020. Data tersebut diunduh dari situs penyedia data historis saham yaitu http://finance.yahoo.com.

\subsection{Metode Analisis}

Tahap-tahap analisis data yang dilakukan untuk pembentukan portofolio dengan metode Markowitz dan pengukuran risiko dengan Expected Shortfall (ES) adalah sebagai berikut:

1. Mengubah data closing price 30 saham JII menjadi data return dengan rumus $R_{i t}=$ $\ln \left[\frac{P_{i t}}{P_{i(t-1)}}\right]$, dimana $P_{i t}$ yaitu harga aset ke-i pada waktu ke-t.

2. Melakukan uji normalitas multivariat terhadap data nilai return dari 30 saham JII. Return aset-aset pembentuk portofolio diasumsikan mengikuti distribusi normal multivariat. Saham-saham yang memenuhi uji normal multivariat adalah CPIN, CTRA, dan BSDE.

3. Menghitung koefisien korelasi saham CPIN, CTRA, dan BSDE.

4. Menghitung return rata-rata (expected return), varian, kovarian, dan standar deviasi saham CPIN, CTRA, dan BSDE.

5. Menentukan bobot aset portofolio menggunakan metode Lagrange.

6. Penentuan portofolio optimal.

7. Mensimulasi nilai return dengan membangkitkan data secara random menggunakan nilai estimasi parameter sebanyak 112 data return dan diulang sebanyak $\mathrm{n}$ kali.

8. Nilai return masing-masing aset pada waktu $t$ yaitu $R_{1 t}, R_{2 t}$ yang dihasilkan pada langkah (7) digunakan untuk menghitung return portofolio pada waktu t yaitu $R p_{t}=w_{1} R_{1, t}+w_{2} R_{2, t}$ dengan $R p_{t} \quad=$ return portofolio pada waktu $\mathrm{t}$ 
$\begin{array}{ll}w_{1} & =\text { besarnya komposisi atau proporsi aset ke-1 } \\ w_{2} & =\text { besarnya komposisi atau proporsi aset ke-2 }\end{array}$

9. Mengestimasi kerugian maksimum pada tingkat kepercayaan $95 \%$ dengan mencari nilai kuantil ke- $(1-\alpha)=0,95$ dari distribusi empiris return portofolio yang dihasilkan pada langkah (8) yang dinotasikan dengan $\mathrm{R}^{*}$.

10. Menghitung nilai VaR pada tingkat kepercayaan $95 \%$ dalam periode waktu 1 hari yaitu:

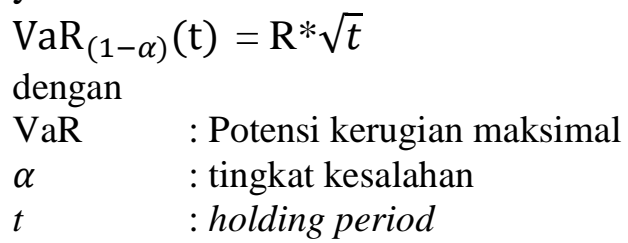

11. Mengulangi langkah (7) sampai (10) sebanyak m sehingga mencerminkan berbagai kemungkinan nilai $\mathrm{VaR}$ portofolio yaitu $\mathrm{VaR}_{1}, \mathrm{VaR}_{2}, \ldots, \mathrm{VaR}_{\mathrm{m}}$

12. Menghitung rata-rata $\mathrm{VaR}$ untuk tingkat kepercayaan $95 \%$ untuk menstabilkan nilai karena nilai VaR yang dihasilkan oleh tiap simulasi berbeda

13. Menghitung nilai Expected Shortfall pada tingkat kepercayaan 95\% dalam periode waktu 5 hari dengan rumus:

$E S_{1-\alpha}=\left(\mu+\sigma \frac{\phi\left(\widehat{V}_{1-\alpha}\right)}{\alpha}\right) \cdot \sqrt{t}$

\section{HASIL DAN PEMBAHASAN}

\subsection{Uji Normalitas Multivariat pada Data Return}

Pengujian asumsi normalitas multivariat untuk data return dapat dilakukan dengan Uji Kolmogorov-Smirnov berikut ini:

Hipotesis

$H_{0}: F\left(d_{j}^{2}\right)=F_{0}\left(d_{j}^{2}\right)$ untuk semua nilai $d_{j}^{2}$

$H_{1}: F\left(d_{j}^{2}\right) \neq F_{0}\left(d_{j}^{2}\right)$ untuk sekurang-kurangnya sebuah nilai $d_{j}^{2}$

Taraf Signifikansi: $\alpha$

Statistik Uji:

$$
D=\sup _{d_{j}^{2}}\left|S\left(d_{j}^{2}\right)-F_{0}\left(d_{j}^{2}\right)\right|
$$

- Untuk portofolio saham CPIN dan CTRA:

$\mathrm{D}=0,0643$ dengan nilai $p$-value $=0,3962$

- Untuk portofolio saham CTRA dan BSDE:

$\mathrm{D}=0,0658$ dengan nilai $p$-value $=0,3789$

- Untuk portofolio saham CPIN dan BSDE:

$\mathrm{D}=0,0734$ dengan nilai $p$-value $=0,2993$

Kriteria Uji:

$\mathrm{H}_{0}$ ditolak jika $\mathrm{D}>\mathrm{D}^{*}(\alpha)$ atau $p$-value $<\alpha$

Keputusan:

Nilai $D^{*}(0,05)$ adalah sebesar 0,1285 . Nilai $D^{*}(0,05)$ diperoleh dari perhitungan $1,36 / \sqrt{ } \mathrm{n}$ dengan $\mathrm{n}=112$ (jumlah data return). Karena nilai $\mathrm{D}<\mathrm{D} *(0,05)$ atau $p$-value $>0,05$ maka $\mathrm{H}_{0}$ diterima.

Kesimpulan:

Return portofolio saham CPIN dan CTRA, CTRA dan BSDE, serta CPIN dan BSDE berdistribusi normal multivariat. 


\subsection{Penentuan Bobot Aset Portofolio}

Penentuan bobot aset portofolio dihitung menggunakan metode Lagrange. Sebelum dilakukan pembobotan terlebih dahulu dilakukan perhitungan rata-rata, standar deviasi dan varian setiap return aset, serta kovarian antar return aset.

- Perhitungan rata-rata return CPIN

$$
\begin{aligned}
\mu_{i} & =\frac{1}{n} \sum_{t=1}^{n} R_{i t}=\frac{1}{112}(-0,1147+0,0979+0,0279+\cdots+(-0,1428)) \\
& =0,4595
\end{aligned}
$$

- Perhitungan varian return CPIN

$$
\begin{aligned}
& \sigma_{i}^{2}=\frac{1}{n-1} \sum_{t=1}^{n}\left(R_{i t}-\mu_{i}\right)^{2}=\frac{1}{111}\left[(-0,1147-0,4595)^{2}+(0,0979-0,4595)^{2}+(0,0279-\right. \\
& \left.0,4595)^{2}+\ldots+(-0,1428-0,4595)^{2}\right]=0,0042
\end{aligned}
$$

- Perhitungan standar deviasi return CPIN

$$
\sigma_{i}=\sqrt{\frac{1}{n-1} \sum_{t=1}^{n}\left(R_{i t}-\mu_{i}\right)^{2}}=\sqrt{0,0042}=0,0645
$$

- Perhitungan kovarian antara return CPIN dan return CTRA

$$
\begin{aligned}
& \sigma_{i j}=\frac{1}{n-1}\left(R_{i t}-\mu_{i}\right)\left(R_{j t}-\mu_{j}\right) \\
& =\frac{1}{111}[(-0,1147-0,4595)(0,0391-(-0,1788))+(0,0979-0,4595)(-0,0043-(-0,1788))+ \\
& \ldots+(-0,1428-0,4595)(-0,0261-(-0,1788)) \\
& =0,0007
\end{aligned}
$$

Perhitungan rata-rata, standar deviasi, varian, dan kovarian yang lainnya dilakukan dengan langkah yang sama. Secara lengkap disajikan pada Tabel 1.

Tabel 1. Rata-Rata, Standar Deviasi, Varian, dan Kovarian

\begin{tabular}{|c|c|c|c|}
\hline Saham & Rata-rata & Standar Deviasi & Varian dan Kovarian \\
\hline CPIN & 0,4595 & 0,0645 & 0,0042 \\
\hline CTRA & $-0,1788$ & 0,0647 & 0,0042 \\
\hline BSDE & $-0,5277$ & 0,0517 & 0,0027 \\
\hline CPIN dan CTRA & - & - & 0,0007 \\
\hline CTRA dan BSDE & - & - & 0,0022 \\
\hline CPIN dan BSDE & - & - & 0,0010 \\
\hline
\end{tabular}

Setelah didapat nilai varian dan kovarian, maka dilakukan perhitungan untuk mendapatkan nilai bobot dengan metode Lagrange. Perhitungan bobot pada saham CPIN dan CTRA adalah sebagai berikut:

$$
\begin{aligned}
& \boldsymbol{\Sigma}^{-\mathbf{1}} \mathbf{1}_{\mathbf{2}}=\left[\begin{array}{ll}
0,00416 & 0,00073 \\
0,00073 & 0,00419
\end{array}\right]^{-1}\left[\begin{array}{l}
1 \\
1
\end{array}\right]=\left[\begin{array}{cc}
247,866 & -43,09351 \\
-43,09351 & 246,36755
\end{array}\right]\left[\begin{array}{l}
1 \\
1
\end{array}\right] \\
& =\left[\begin{array}{l}
204,77249 \\
203,27404
\end{array}\right] \\
& \mathbf{1}_{2}{ }^{\boldsymbol{T}} \boldsymbol{\Sigma}^{-\mathbf{1}} \mathbf{1}_{\mathbf{2}}=\left[\begin{array}{ll}
1 & 1
\end{array}\right]\left[\begin{array}{cc}
247,866 & -43,09351 \\
-43,09351 & 246,36755
\end{array}\right]\left[\begin{array}{l}
1 \\
1
\end{array}\right]=[408,04653] \\
& \boldsymbol{w}=\frac{\boldsymbol{\Sigma}^{-\mathbf{1}} \mathbf{1}_{\mathbf{2}}}{\mathbf{1}_{\mathbf{2}} \boldsymbol{\Sigma}^{\mathbf{- 1}} \mathbf{1}_{\mathbf{2}}}=\frac{\left[\begin{array}{l}
204,77249 \\
203,27404
\end{array}\right]}{[408,04653]}=\left[\begin{array}{l}
0,50184 \\
0,49816
\end{array}\right]
\end{aligned}
$$

Perhitungan untuk portofolio yang lainnya dapat dilakukan dengan langkah yang sama. Secara lengkap, bobot alokasi dana untuk 2 saham portofolio disajikan pada Tabel 2. Tabel 2. Bobot Alokasi Dana

\begin{tabular}{|c|c|}
\hline Kombinasi Portofolio & Bobot $(\%)$ \\
\hline CPIN dan CTRA & $50,2: 49,8$ \\
CTRA dan BSDE & $18,5: 81,5$ \\
CPIN dan BSDE & $34,7: 65,3$ \\
\hline
\end{tabular}




\subsection{Perhitungan Portofolio Optimal}

Berikut perhitungan standar deviasi portofolio terhadap saham CPIN dan CTRA, CTRA dan BSDE, serta CPIN dan BSDE menggunakan persamaan berikut:

$$
\begin{aligned}
& \sigma_{p}^{2}=\sum_{i=1}^{n} w_{i}^{2} \sigma_{i}^{2}+2 \sum_{i=1}^{n} \sum_{j<i}^{n} w_{i} w_{j} \sigma_{i j}, \quad i \neq j \\
& \text { Dimana, } \\
& \sigma_{i j}=\rho_{i j} \sigma_{i} \sigma_{j} \\
& \sigma_{p}=\sqrt{\sigma_{p}^{2}} \\
& \sigma_{p}=\sqrt{w_{C P I N}^{2} \sigma_{C P I N}^{2}+w_{C T R A}^{2} \sigma_{C T R A}^{2}+2 w_{C P I N} w_{C T R A} \rho_{C P I N, C T R A} \sigma_{C P I N} \sigma_{C T R A}} \\
& =\sqrt{\begin{array}{c}
(0,502)^{2}(0,06451)^{2}+(0,498)^{2}(0,06470)^{2}+ \\
2(0,502)(0,498)(0,17596)(0,06451)(0,06470)
\end{array}} \\
& =0,0495 \\
& \sigma_{p}=\sqrt{w_{C T R A}^{2} \sigma_{C T R A}^{2}+w_{B S D E}^{2} \sigma_{B S D E}^{2}+2 w_{C T R A} w_{B S D E} \rho_{C T R A, B S D E} \sigma_{C T R A} \sigma_{B S D E}} \\
& =\sqrt{(0,185)^{2}(0,06470)^{2}+(0,815)^{2}(0,05165)^{2}+} \\
& =0,0508 \\
& \sigma_{p}=\sqrt{w_{C P I N}^{2} \sigma_{C P I N}^{2}+w_{B S D E}^{2} \sigma_{B S D E}^{2}+2 w_{C P I N} w_{B S D E} \rho_{C P I N, B S D E} \sigma_{C P I N} \sigma_{B S D E}} \\
& =\sqrt{\begin{array}{c}
(0,347)^{2}(0,06451)^{2}+(0,653)^{2}(0,05165)^{2}+ \\
2(0,347)(0,653)(0,29396)(0,06451)(0,05165)
\end{array}} \\
& =0,0456
\end{aligned}
$$

Dari hasil perhitungan nilai standar deviasi portofolio diatas, didapatkan nilai standar deviasi terkecil dari kombinasi dua saham yaitu 0,0456 dengan bobot $\mathrm{CPIN}=34,7 \%$ dan $\mathrm{BSDE}=65,3 \%$ yang artinya portofolio optimal dari kombinasi dua saham tersebut adalah portofolio saham CPIN dan BSDE.

\subsection{Analisis Perhitungan Value at Risk (VaR)}

Pada tingkat kepercayaan 95\% dengan 600 kali perulangan, dihasilkan rata-rata nilai VaR sebesar 0,152606 (bernilai positif dengan asumsi bahwa nilai VaR kerugian yang akan diderita investor tidak akan melebihi 15,2606\%). Misalkan dana investasi awal sejumlah Rp 100.000.000, maka estimasi kerugian maksimal yang akan diterima oleh investor diperkirakan akan mencapai Rp 15.260.600.

\subsection{Analisis Perhitungan Expected Shortfall (ES)}

Perhitungan ES untuk tingkat kepercayaan 95\% dengan menggunakan persamaan berikut:

$$
\begin{aligned}
& \mathrm{ES}_{1-\alpha}=\left(\mu+\sigma \frac{\phi\left(\vec{V}_{1-\alpha}\right)}{\alpha}\right) \cdot \sqrt{t} \\
& \mathrm{ES}_{95 \%}=\left(-0,00165+0,04564 \frac{0,1031}{0,05}\right) \cdot \sqrt{5}=0,206727
\end{aligned}
$$

Pada tingkat kepercayaan 95\% diperoleh nilai ES sebesar 0,206727 (bernilai positif dengan asumsi bahwa nilai ES tetap menunjukan kerugian yang akan diderita). Nilai ES $(0,206727)$ lebih besar dibandingkan dengan nilai $\operatorname{VaR}(0,15512)$ pada taraf signifikansi yang sama. Misalkan dana investasi awal sejumlah Rp 100.000.000, maka estimasi 
kerugian maksimal yang bakal diderita oleh investor diperkirakan akan mencapai Rp 20.672.700.

\subsection{GUI Matlab}

Tampilan GUI untuk portofolio optimal Metode Markowitz dan analisis risiko dengan Expected Shortfall (ES) dapat dilihat pada Gambar 1 berikut.

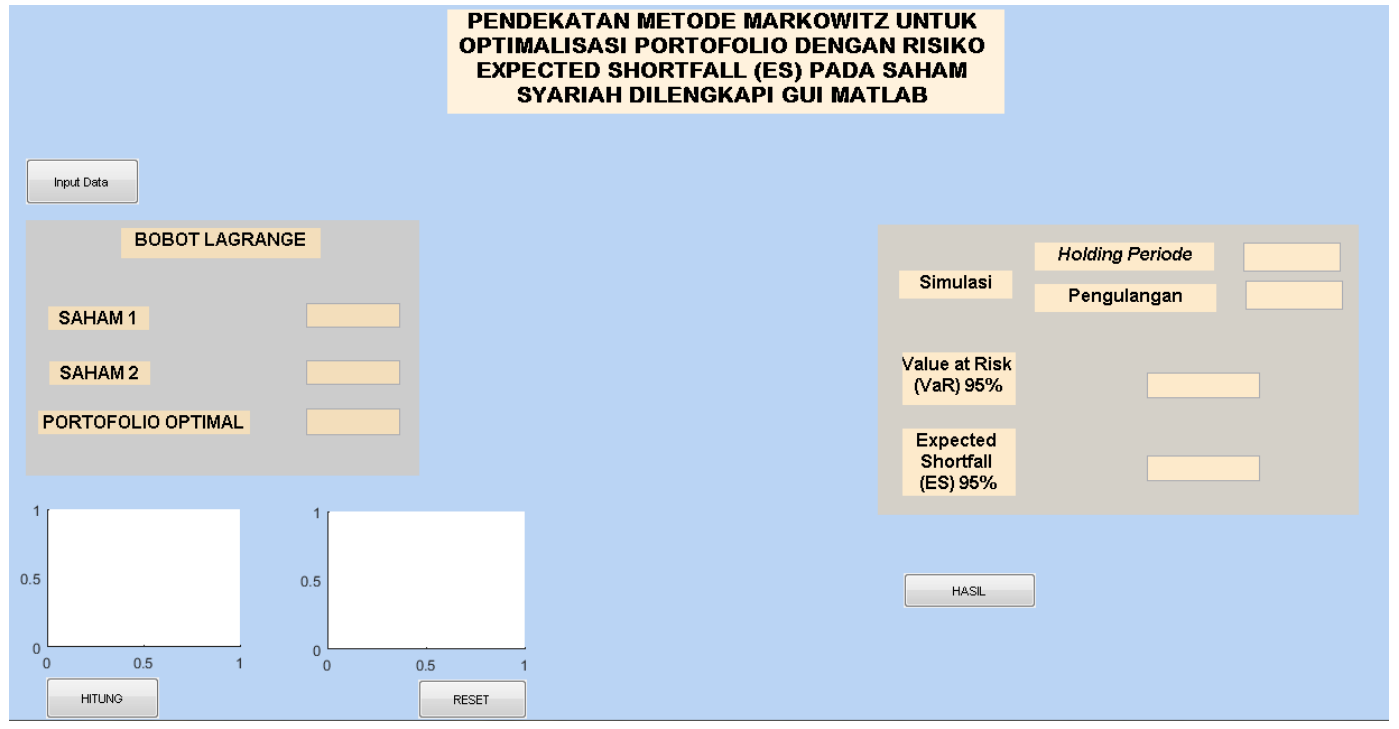

Gambar 1. Tampilan Portofolio Optimal Metode Markowitz dan Perhitungan Risiko dengan ES

\section{KESIMPULAN}

Berdasarkan hasil analisis dan pembahasan dapat disimpulkan bahwa:

1. Dari 30 saham JII terpilih 3 saham yang memenuhi asumsi normalitas multivariat untuk dibentuk portofolio optimal menggunakan Metode Markowitz, yaitu saham CPIN, CTRA, dan BSDE.

2. Hasil portofolio optimal dari kombinasi tiga saham dengan portofolio 2 saham menggunakan bobot Lagrange adalah 0,0456 dengan berinvestasi ke saham CPIN = $34,7 \%$ dan $\mathrm{BSDE}=65,3 \%$.

3. Hasil perhitungan Expected Shortfall (ES) memperhitungkan kerugian diatas nilai Value at Risk (VaR). Hasil perhitungan nilai Expected Shortfall (ES) untuk tingkat kepercayaan $95 \%$ diperoleh nilai $(0,206727)$ lebih besar dibandingkan dengan nilai $\operatorname{VaR}(0,15512)$.

\section{DAFTAR PUSTAKA}

Afriana, T., Tarno, dan Sugito. 2017. Analisis Pembentukan Portofolio pada Perusahaan yang Terdaftar Di Lq45 dengan Pendekatan Metode Markowitz Menggunakan Gui Matlab. Jurnal Gaussian. Vol. 6(2):251-260. Semarang: UNDIP

Jorion, P., 2000. Value at Risk: The New Benchmark for Managing Financial Risk. Second Edition. The McGraw-Hill Companies: Inc. New York.

Maruddani, D.A.I. dan Purbowati, A., 2009. Pengukuran Value at Risk Pada Aset Tunggal dan Portofolio dengan Simulasi Monte Carlo. Media Statistika. Vol. 2(2):93-104. Semarang: UNDIP.

Maruddani, D.A.I. 2019. Value at Risk untuk Pengukuran Risiko Investasi Saham : Aplikasi dengan Program R. Jawa Timur: Wade Group. 
McNeil, A. J., R. Frey dan P. Embrechts, 2005. Quantitative Risk Management. Pricenton University Press and Oxford.

Rockafellar, R.T., and Uryasev, S., 2000. Optimization of Conditional Value at Risk. Journal of Risk, Vol. 2, No. 3.

Tandelilin, E. 2010. Portofolio dan Investasi Teori dan Aplikasi, Edisi Pertama. Yogyakarta: Kanisius.

http://finance.yahoo.com. Diakses pada 15 Februari 2020. 